\title{
On the Cultivation of Comprehensive Quality of Martial Arts Specialized
}

\section{Students}

\author{
Feng Jianfu
}

Construction Bureau, Neijiang Vocational and Technical College, Neijiang, Sichuan, 641000, China

Key words: knowledge economy; quality; Martial Arts talent; Martial Arts education

\begin{abstract}
In the era of knowledge economy, the author puts forward new requirements for the quality of Martial Arts talents in the 21st century. At the same time, it also brings opportunities and challenges to the development of Martial Arts education. Only by changing the educational thought, optimizing the quality of teachers, updating the teaching content, innovating teaching methods, creating a good campus culture atmosphere, and updating the evaluation system of Martial Arts education can we train high-quality Martial Arts talents in line with the needs.

The training of higher education personnel directly affects the quality of basic education. The requirements of the reform and development of basic education are the basis and starting point of the mode of personnel training in normal universities. Facing the 21st century, cultivating the "broad foundation, post-knowledge and high-quality" talents is our historical mission and the practical problem in the educational reform. To cultivate the comprehensive quality of Martial Arts students, we must first adhere to the Socialism Education Direction, having moral, intellectual, physical, beauty, labor and comprehensive development. Second, we must adapt to the needs of the future, adjust their curriculum and knowledge structure, and create a knowledge level of enormous potential, including basic cultural knowledge, professional and technical knowledge and professional frontier; the change of the training model to adapt to social and student diversity options.
\end{abstract}

\section{The overall quality of Martial Arts students training requirements}

At present, the general trend of world higher education development for the 21st century is: to strengthen the overall quality of personnel training through scientific construction and adjustment. An ideal college students should have three criteria: First, there is professional knowledge and the discipline of the methodology; Second, the combination of the major, the actual life and other disciplines; third is a good personality quality. Although our country's Martial Arts education policy and education objectives are different from that in Western countries, the motive for its reform and development is similar. The driving force is that the more economic growth and social development, the more requirements of Martial Arts personnel there will be to provide high-quality service for the community.

Economic life, cultural life and social prosperity and development need to cultivate a complex knowledge of Martial Arts talent. The development of Economy and automatic production has reduced people's labor work, shortened labor time. The lack of exercise requires a group of Martial Arts program managers and health guidance, who are both the master of theory and education, and the manager of the competition, entertainment and fitness with a high cultural and artistic accomplishment. 


\section{The Structure and Characteristics of Overall Martial Arts Specialized Students}

A Martial Arts Specialized Students should have the correct Martial Arts values, strong sense of social responsibility, and profoundly understanding of the great significance and value of Martial Arts for human society, as well as a comprehensive understanding of Martial Arts on politics, economy, culture, fitness, entertainment, education, social and other promotion aspects; Lifelong engagement in Martial Arts training and development of Martial Arts ideology; the initiative to learn Martial Arts knowledge and skills and participate in academic exchanges.

Students generally should have a good body shape, physical function, physical fitness, physical resistance to disease, strong tolerance, a strong Interest, good participation motivation, the ability to correctly understand, analyze, evaluate themselves, self-regulation, self-motivation, self-demand, and self-esteem, self-love, self-reliance and self-consciousness. In addition, they should also have the perseverance and willpower to bear the frustration and pain and explore the new quality and style of Martial Arts.

A person with a high cultural quality and cultural character is not only consciously cultivating the results, but also the result of a particular cultural infection. Reasonable Improvement of Knowledge Structure is the "Software" Foundation and Source of Martial Arts Talents. Correspondingly, they are rich in cultural knowledge, have certain knowledge of humanities and social sciences, especially traditional knowledge of philosophy, Martial Arts theory, Martial Arts aesthetics, Martial Arts history and other knowledge, profoundly understand the internal structure of Martial Arts and its running rules, and are familiar with Martial Arts and politics, Economic, military, cultural, artistic, educational and other social phenomena.

Martial Arts requires a good physical fitness, including sensitivity, coordination, flexibility and strength, speed, bounce and other qualities, and the psychological capacity; can learn to use and be proficient in boxing, mastering a variety of Martial Arts routine and wrestling movement related to the basic technology.

Innovation quality is also the core of its comprehensive quality and the ultimate destination. A keen sense of innovation requires the development of creation, seeking difference seeking and innovative thinking.

\section{The Cultivation of Comprehensive Quality of Martial Arts Specialized Students}

Change the concept of Martial Arts education based on inheritance, and establish the concept of Martial Arts education with emphasis on cultivating innovative spirit. Inheritance is only the basis and premise of innovation. We should put students' learning ability, innovation consciousness, innovative thinking, innovation spirit and innovation ability in the first.

Take active and effective measures to co-ordinate the development and plan, through self-learning, training and other forms to strengthen the education of Martial Arts teachers, and constantly reconstruct their educational concepts, talent quality, professional ethics, humanistic quality, professional and technical quality, work content and focus; grasp the academic leaders, and develop more scientific selection, training programs and assessment, the implementation of equal competition.

Based on the principle of thick foundation and wide caliber, it is necessary to cultivate students' solid basic knowledge and skills in curriculum setting, but also strengthen practical teaching links, implement interdisciplinary and cross-school curriculum; strengthen cultural quality and humanistic quality education, broaden the students' scientific horizons, and incorporate them into teaching programs. At the same time, reform the curriculum system, do a good job of the 
convergence of various courses and the implementation of the integration.

Strengthen the teaching, research and application of modern educational technology and means, increase the necessary input, constantly update the teaching equipment and equipment; to strengthen the teaching staff to master and apply the modern educational technology ability training; focus on the development and use of computer-centric multimedia. Introduce remote technology and network technology into teaching, and actively develop computer-aided teaching, training students' awareness of modern teaching and training and the use of modern teaching and training methods of knowledge and ability.

We should vigorously carry out a variety of campus cultural activities, create a relaxed and harmonious and democratic, people-oriented, student-centered living environment. At the same time, we must pay attention to the construction of the campus human environment, the construction of some beautiful natural landscape, cultural landscape, the formation of a good academic and cultural atmosphere, and promote the cultivation of innovative Martial Arts talent.

The evaluation of the subject should include teachers' teaching, student learning and curriculum settings. Second, the evaluation content should include formative evaluation and summary evaluation. Among them, the formation of evaluation is mainly on how teachers teach, how students learn and how to arrange and organize the course. The quality evaluation should include the students' quality, psychological quality, ideological and moral quality, innovative quality and the cultivation of practical ability, the scientific nature of the curriculum, adaptability and effectiveness of the curriculum of Martial Arts. Finally, the evaluation method should base on the self-evaluation and use expert evaluation, peer evaluation, student evaluation method.

\section{Conclusion}

Martial Arts education is different from other education, because of the distinctive characteristics of the Chinese tradition, to be in line with international standards, must be consistent with the spirit of the times. Therefore, training new Martial Arts talent is imperative. Martial Arts education should not only be regarded as a kind of thought and idea, an educational principle, but also as an activity to run through the practice of Martial Arts education. At the same time, how to improve the understanding of the law of innovation, conscious and continuous application of the law in the field of Martial Arts teaching, is a crucial issue now and in the future.

\section{References}

[1] Wang Shuntang, Creative teaching in the process of Physical Education, Journal of Shenyang Sports Institute, 2001.1.

[2] Zhang Zisha, Study on the quality education in Chinese universities, PE Science, 2001.12.

[3] Dai Jian, Requirement for the cultivation of $21^{\text {st }}$ PE talents. Journal of Shanghai Sports Institute, 2001. 25.

[4] Zhang Huihong, On the Cultivation of $21^{\text {st }} \mathrm{PE}$ talents, Journal of Chengdu Sports Institute, 2001.6.

[5] Wang Shengli, The constitution and cultivation of PE students' creativity, Journal of Shenyang Sports Institute, 2002,3. 